\title{
PROGRAMA MAIS EDUCAÇÃO: A EDUCAÇÃO AMBIENTAL NA ESCOLA DE TEMPO INTEGRAL
}

Elizabete Aparecida SOLA ${ }^{1}$

Marília Andrade TORALES ${ }^{2}$

RESUMO: O referido trabalho inicia falando sobre o momento importante que a educação pública brasileira está vivendo e de que a sociedade se mostra cada vez mais envolvida e participativa, buscando e exigindo uma educação pública igualitária e de qualidade. Destaca brevemente o Programa Mais Educação (BRASIL, 2012a) que foi inspirado em Anísio Teixeira, Darcy Ribeiro e Paulo Freire e que possui atividades optativas agrupadas em macrocampos. Por fim o trabalho parte de investigar as atividades de educação ambiental realizadas nas escolas de ensino integral da Rede Municipal de Ensino de Curitiba e nos traz uma experiência vivenciada, relatando-nos as atividades desenvolvidas com educação ambiental dentro do espaço da escola de ensino integral.

PALAVRAS-CHAVE: Programa mais educação. Educação ambiental. Ensino integral.

\section{Introdução}

A partir da Constituição Federal Brasileira de 1988, nossa sociedade teve a oportunidade de perceber e compreender mais a complexidade de elementos que sustentam o seu direito de uma educação mais igualitária e de qualidade. Neste sentido, Moll (2012) ressalta que, vivemos um momento muito especial da educação pública em nosso país, com a implantação de programas preocupados em atingir as mais variadas classes sociais, independentemente da etnia, crença ou cultura. Embora saibamos que ainda há muito a se fazer, esse caminhar em busca de uma educação igualitária e de qualidade é um desafio fundamental posto a toda cidadania.

Entre alguns programas ${ }^{3}$ inspirados em Anísio Teixeira, Darcy Ribeiro e Paulo Freire, o Programa Mais Educação (BRASIL, 2012a), criado pela Portaria Interministerial no 17/2007, operacionalizado pela Secretaria de Educação Continuada, Alfabetização e Diversidade (SECAD) tem por objetivo aumentar a oferta educativa nas

\footnotetext{
1 Mestranda em Educação. UFPR - Universidade Federal do Paraná. Pós-Graduação em Educação. Curitiba - PR - Brasil. 80060-150 - eliza.sola@ig.com.br.

2 Professora em Educação. UFPR - Universidade Federal do Paraná. Pós-Graduação em Educação. Curitiba - PR - Brasil. 80060-150 - mariliat.ufpr@gmail.com.

${ }^{3}$ Plano de Desenvolvimento da Educação (PDE), Fundo de Manutenção e Desenvolvimento Educação Básica e de Valorização dos Profissionais da Educação (FUNDEB), Índice de Desenvolvimento da Educação Básica (IDEB), Programa Mais Educação.
} 
escolas públicas, por meio de um ensino de educação integral, com atividades optativas agrupadas em macrocampos ${ }^{4}$ :

Acompanhamento Pedagógico (matemática, letramento, línguas estrangeiras, ciências, história e geografia, filosofia, sociologia);

Meio Ambiente (Com Vidas, Agenda 21 na escola, educação para a sustentabilidade, horta escolar e/ou comunitária);

Esporte e Lazer (atletismo, ginástica rítmica, corrida de orientação, ciclismo, tênis de campo, recreação/lazer, voleibol, basquete, basquete de rua, futebol, futsal, handebol, tênis de mesa, judô, karatê, taekwondo,ioga, natação, xadrez tradicional, xadrez virtual, Programa Segundo Tempo (ME));

Direitos Humanos em Educação (direitos humanos e ambiente escolar);

Cultura e Artes (leitura, banda, fanfarra, canto coral, hip hop, danças, teatro, pintura, grafite, desenho, escultura, percussão, capoeira, flauta doce, cineclube, prática circense, mosaico);

Cultura Digital (software educacional, informática e tecnologia da informação (PROINFO), ambiente de redes sociais);

Promoção da Saúde (atividades de: alimentação saudável/alimentação escolar saudável, saúde bucal, práticas corporais e educação do movimento, educação para a saúde sexual, saúde reprodutiva e prevenção DST/AIDS, prevenção ao uso de álcool, tabaco e outras drogas, saúde ambiental, promoção da cultura de paz e prevenção em saúde a partir do estudo dos principais problemas de saúde da região (dengue, febre amarela, malária, hanseníase, doença falciforme, e outras);

Educomunicação (jornal escolar, rádio escolar, histórias em quadrinhos, fotografia, vídeo);

Iniciação no Campo das Ciências da Natureza (laboratório, feira de ciências e projetos científicos);

Educação Econômica (educação econômica e empreendedorismo, controle social e cidadania).

\section{Desenvolvimento}

\footnotetext{
${ }^{4}$ Disponível em: <http://portal.mec.gov.br/dmdocuments/passoapasso_maiseducacao.pdf >. Acesso em: 5 fev. 2014.
} 
O Plano Nacional de Educação (PNE) (BRASIL, 2012b) tem como 6 ${ }^{\text {a }}$ meta oferecer educação em tempo integral em $50 \%$ das escolas públicas de educação básica, ou seja, um ensino 5 dias por semana com no mínimo 7 horas por dia. As escolas participantes do Programa Mais Educação recebem através do Programa Dinheiro Direto na Escola (PDDE) um acréscimo em questão de merenda e kits escolares e tem autonomia na escolha das atividades optativas, os “macrocampos” que serão abordados no turno contrário ao frequentado regularmente pelo aluno. Essas atividades optativas deverão estar presentes no Projeto Político Pedagógico (PPP) de cada instituição e cabe a escola selecionar os alunos que freqüentarão a escola em regime integral.

No estado do Paraná temos atualmente 329 escolas participantes do Programa Mais Educação, estando presente em 32 municípios. A Rede Municipal de Ensino de Curitiba (RME) é composta por 552 unidades, sendo 181 municipais entre as quais, 37 são centros de educação integral.

Nesse caso, uma escola municipal da cidade de Curitiba (CURITIBA, 2012), é usada como exemplo nesse referido trabalho para demonstrar as ações que estão sendo realizadas com atividades de educação ambiental dentro do seu espaço de ensino integral. Essa escola atende no período da manhã 286 alunos e 274 alunos no período da tarde. Em abril de 2012 começou seu processo de ampliação para ensino integral dentro do Programa Mais Educação e atende os alunos que foram previamente selecionados para realizaram as atividades optativas do Programa, sendo até o momento 113 alunos participantes.

As atividades (MACROCAMPOS) realizadas na escola significaram numa mudança de postura de todos os envolvidos nesse processo, numa maior integração entre pais/escola e comunidade. Em reuniões de planejamento realizadas na escola, o corpo docente mostrou-se mais atento as necessidades dos alunos e aos problemas ambientais e sociais entorno da escola. Notou-se que, em apenas 4 meses de implantação do Programa Mais Educação os alunos envolvidos no programa desenvolveram mais a sua autonomia, participação, interesse, responsabilidade e empatia.

Destacamos principalmente as atividades voltadas para o Meio Ambiente, Cultura e Artes e Educomunicação. A Horta escola tem rendido bons frutos e os alunos envolvidos têm se mostrando engajados nessa atividade e demonstrado na escola e em casa uma preocupação com o meio ambiente, assumindo uma postura mais responsável e consciente. Nas atividades teatrais os alunos realizaram apresentações para os alunos e 
a comunidade enfatizando a importância da água em nossas vidas e quais cuidados podem adotar para sua preservação. Nas atividades de Educomunicação, os alunos utilizaram o jornal da escola para entrevistarem os colegas, os professores e os pais sobre o que entendem sobre meio ambiente e se praticam ações voltadas para a sustentabilidade.

\section{Considerações finais}

Estamos presenciando um momento único e histórico da educação pública brasileira, o qual a sociedade tem se mostrado cada vez mais engajada e participativa, buscando uma educação motivadora e condizente com a realidade presente em cada comunidade escolar.

Na perspectiva de alcançarmos essa qualidade, o Programa Mais Educação, vem sendo um meio que possibilita trabalhar com as mais variadas atividades que não estão presentes no currículo formal, mas, que são de extrema valia para o desenvolvimento dos alunos e o resgate dos valores morais e éticos.

Em busca de se entrelaçar os conteúdos do currículo formal e não formal para se trabalhar a educação ambiental de forma consciente, Guattari (2009) estabelece que a Ecologia Ambiental não seja única, e que está naturalmente interligada a Ecologia Social e a Ecologia Mental; e que as medidas políticas cabíveis para a recuperação do nosso planeta, estão condicionadas às atitudes mentais individuais e sociais dos cidadãos.

A educação ambiental presente nas escolas de ensino integral tem um papel essencial para facilitar o entendimento dos alunos, professores e comunidade escolar sobre as questões ambientais e possibilita o trabalho com os mais variados assuntos. Dias (2004) nos ressalta que a educação ambiental por ser interdisciplinar pode e deve ser o agente otimizador de novos processos educativos que possibilita a mudança e melhoria do ambiente e da qualidade da sua experiência humana.

O trabalho envolvendo a educação ambiental nas escolas de ensino integral requer de todos nós, um real comprometimento, almejando instigar ações significativas que despertem a atenção dos alunos, pais, professores e toda comunidade escolar. Uma busca efetiva para uma mudança comportamental, tornando-nos cidadãos mais responsáveis e conscientes das ações que praticamos com os outros e com o meio ambiente. 
MORE EDUCATION PROGRAM: ENVIRONMENTAL EDUCATION IN SCHOOL FULL TIME

ABSTRACT: That work begins talking about the important moment that public education in Brazil are living and that the company is showing more and more involved and participatory, seeking and demanding a public education and equal quality. More highlights briefly Education Program which was inspired by Teixeira, Darcy Ribeiro and Paulo Freire and has optional activities grouped into macrocampos. Finally the work of investigating the environmental education activities performed in schools teaching the full Municipal School of Curitiba and brings an experience, reporting on the activities with environmental education within the space of elementary school full.

KEYWORDS: More education program. Environmental education. Comprehensive education.

\section{REFERÊNCIAS}

BRASIL. Ministério da Educação. Programa mais educação: passo a passo. [2012a]. Disponível em:

<http://portal.mec.gov.br/dmdocuments/passoapasso_maiseducacao.pdf>

Acesso em: 4 ago. 2012.

BRASIL. Ministério da Educação. Programa Nacional de Educação. [2012b]

Disponível em:

$<$ http://portal.mec.gov.br/index.php?option=com_content\&view=article\&id=16478\&Ite mid=1107> . Acesso em: 4 ago. 2012.

CURITIBA. Prefeitura Municipal de Curitiba. Cidade do conhecimento. [2012]

Disponível em:

$<$ http://www.cidadedoconhecimento.org.br/cidadedoconhecimento/index.php?op=sme\& sel_estabe=1\&sel_bairro=0\#>. Acesso em: 4 ago. 2012. Escolas da Rede Municipal de Ensino de Curitiba.

DIAS, G. F. Educação ambiental: princípios e práticas. 9.ed. São Paulo: Gaia, 2004.

GUATTARI, F. As três ecologias. 2.ed. rev. ampl. São Paulo: Brasiliense, 2009.

MOLL, J. Caminhos da educação integral no Brasil: direito a outros tempos e espaços educativos. Porto Alegre: Penso, 2012. 